\title{
The role of adenosinergic pathway in human autoimmune diseases
}

\author{
Ke Dong ${ }^{1} \cdot$ Zhao-wei Gao $^{1} \cdot$ Hui-zhong Zhang ${ }^{1}$
}

Published online: 24 September 2016

(c) The Author(s) 2016. This article is published with open access at Springerlink.com

\begin{abstract}
Autoimmune diseases are characterized by the abnormal immune response against self-tissue, which are caused by the failure of nature immune homeostasis. Nature immune homeostasis represents the normal state of appropriate immune response to nonself-antigen and unresponsiveness to self-antigens. In normal situation, immune homeostasis is regulated by immunosuppressive signal and immunostimulating signal together. Accumulating data have demonstrated that the adenosinergic pathway played key roles in immune suppression and shield body from an excessive inflammatory response. The deficiency of adenosinergic pathway results in the imbalance between the pro- and anti-inflammatory activities. Thus, researchers pay much attention to the role of adenosinergic pathway in autoimmune diseases development. To date, accumulating data have suggested an important role of adenosinergic pathway-related molecules (i.e., CD39, CD73, ADA, adenosine receptors, etc.) in many types of human autoimmune diseases. More importantly, these findings have presented potential value of adenosinergic pathway analysis to be used for autoimmune diseases diagnosis, monitoring and treatment. In this review, we will provide a comprehensive description of the role of adenosinergic pathway in human autoimmune diseases.
\end{abstract}

Ke Dong

tdjyk3@fmmu.edu.cn

1 Department of Clinical Diagnosis, Tangdu Hospital, Fourth Military Medical University, Xi' an, China
Keywords Adenosinergic pathway - Adenosine receptor . Immunosuppression · Autoimmune diseases

\section{Introduction}

Autoimmune diseases are caused by the deficiency or losing of nature immune tolerance. Under certain circumstance, immune system attacks the self-antigens, following with excessive immune response, which leads to autoimmune diseases to happen $[1,2]$. The autoimmune diseases may be restricted to certain tissues, organs or the whole body. The frequent autoimmune diseases include RA (rheumatoid arthritis), SLE (systemic lupus erythematosus), MS (multiple sclerosis), T1DM (Type I diabetes mellitus), JIA (Juvenile idiopathic arthritis), AIH (autoimmune hepatitis), etc. The basic function of human immune system is distinguishing antigens and then eliminates the nonself-antigens and protects the body from infection, tumor, etc. In normal situation, there is "alarm" signal which generates various cellular responses that aim to prevent excessive inflammatory response and restore the immune homeostasis. Several lines of evidence have demonstrated that adenosine behaves as the "alarm" signal in vivo. Adenosine activates adenosine receptors on target cells, generates multiple cellular responses and then suppresses the immune response [3,4]. Thus, deficiency of adenosinergic pathway may result in the disorder of immune response. Recent years, researchers pay much attention to the role of adenosinergic pathway in autoimmune disease development. This present review will provide a comprehensive description of the role of adenosinergic pathway in human autoimmune diseases. 


\section{Adenosinergic pathway regulates immune imbalance during autoimmune diseases progression}

\section{Immune imbalance in autoimmune diseases}

Autoimmune diseases arise from an abnormal immune response against self-tissues and cells and lead to the injury. In normal situation, the immune response is regulated by immunosuppressive signal and immunostimulating signal together. A fine balance between immunosuppressive and immunostimulating signals is important for maintaining the homeostasis of immune system. Accumulating data have shown that disturbed balance of immune system was involved in development of autoimmune diseases. The main $\mathrm{T}$ cell subsets which are pivotal for this $\mathrm{T}$ cell balance consist of $\mathrm{T}$ helper (Th) cells and regulatory $\mathrm{T}$ (Treg) cells, and moreover, Th cells are defined as Th1, Th2 and Th17 subtypes characterized by differential expression of certain cytokines. In SLE, increasing evidences have demonstrated that the disrupted balance between Th cells and Treg cells contributed to the disease development [5-9]. Deficiencies of Treg cells, either quantitative or functional, were found in active lupus patients, while the number of Th17 cells, as well as Th17related cytokines, was found increased in SLE patients [10-12]. Studies have reported higher concentration of IL17 in the serum and synovial fluid of RA patients compared to controls $[13,14]$. IL-17 is the main cytokine secreted by Th17 cells, which indicated that the number and/or activity of Th17 cells was increased in RA patients, while studies showed that the percentage of circulating Treg cells in RA patients was reduced compared to healthy controls [15]. Similarly, imbalance of Th cells and Treg cells has been noted in T1DM [16]. The imbalance is manifested by expansion of Th17 cells which is concomitant with decreased number or function of Treg cells. Taken together, above data demonstrated that the disrupted homeostasis of immune system played a critical role in the autoimmune diseases development.

\section{Adenosine signaling pathway}

Adenosine is an important immunosuppressive signal in the internal environment, which can shield cells and tissues from an excessive inflammatory response and immunemediated damage [4, 17]. Extracellular adenosine concentration is determined by a complex ectoenzyme mechanism and uptake system [3, 18]. The generation of adenosine in the internal environment is regulated by a cascade of enzyme (Fig. 1). Adenosine is generated from degradation of ATP which is catalyzed by the enzyme cascade as follows: ATP/ADP breakdown into AMP by CD39 (ecto-nucleoside triphosphate diphosphohydrolase 1, E-NTPDase1), AMP breakdown into adenosine by CD73 (ecto-5'-nucleotidase, NT5E). Adenosine can be catalyzed into inosine by ADA (adenosine deaminase) and its cofactor CD26 (dipeptidyl peptidase 4). Uptake system, which includes ENTs (equilibrative nucleoside transporters) and CNTs (concentrative nucleoside transports), shunt extracellular adenosine into the intracellular space, thereby regulating the concentration of extracellular adenosine and terminating adenosine receptor signaling. Adenosine activates its G-protein-coupled cell-surface receptors on target cells, which generate various cellular responses that aim to restore immune homeostasis. Up to date, four adenosine receptors have been identified: A1R, A2AR, A2BR and A3R. A1R, A2AR and A2BR are conserved and highly homologous (80-95\%), whereas A3R varies substantially among different species [19]. Adenosine receptor signaling depends on the level of extracellular adenosine. Accumulating data have demonstrated that adenosine behave as an immunosuppressive signal via activating its receptors.

\section{Adenosine pathway mediate immune suppression}

Accumulated data have shown that adenosinergic pathwaymediated immune suppression and played an important role in maintaining the homeostasis of immune system (Fig. 1). The regulatory T cells (Treg cells), also known as suppressor $\mathrm{T}$ cells, are a subpopulation of $\mathrm{T}$ cells which modulate the immune response and maintain immunological tolerance. Treg cells generally suppress immune response by suppressing the proliferation and function of effect $\mathrm{T}$ cells. Romio et al. showed that the suppressive function of Treg cells was dependent on the CD73 expression on Treg cells surface. They found that CD73positive Treg cells strongly inhibited proliferation of $\mathrm{CD} 4{ }^{+} \mathrm{CD} 25^{-}$-effective $\mathrm{T}$ cells in co-culture experiments, while there was no significant inhibited function when experiments were performed with Treg cells lacking CD73 [20].

Smyth et al. [21] found that Treg cells suppressed effective $\mathrm{T}$ cells via the production of secreted membrane vesicles, such as exosomes. Moreover, their results showed that CD73 was expressed on Treg-derived exosomes and contributed to Treg cell's suppressive activity through the production of adenosine. The exosomes derived from CD73-positive Treg cells can significantly inhibit CD4 ${ }^{+-}$ CD25- effect $\mathrm{T}$ cells proliferation, while the exosomes derived from a CD73-negative Treg cells lack the suppressive capacity. Notably, the suppressive capacity of exosomes derived from CD73-positive Treg cell is in a 
Fig. 1 Adenosine pathway mediates immune suppression. A scheme illustrates the generation of adenosine and the adenosine receptor signaling pathway that mediates immune suppression. Adenosine is generated from degradation of ATP by CD39 \& CD73. The adenosine pathway mediates the immune suppression by regulating the function of immune cells, such as T cells, dendritic cells and macrophages

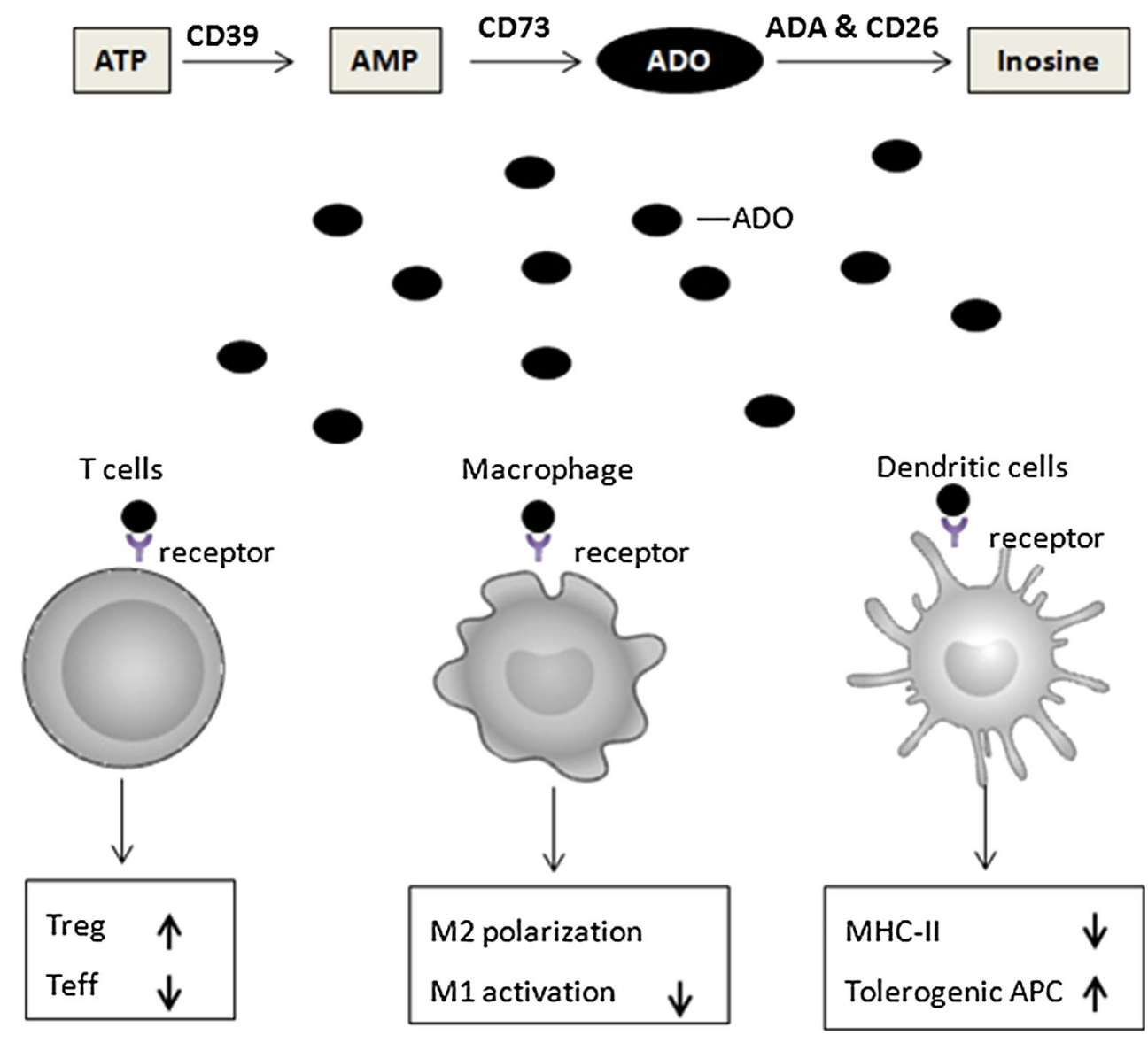

that adenosine pathway played a key role in the suppression of inflammatory response.

\section{Adenosine pathway changes in human autoimmune diseases}

Development of autoimmune diseases is associated with the deficiency of immune-suppressive signal, in which the adenosine has been demonstrated to play an important role. Therefore, researchers pay attention to study the role of adenosine pathway in autoimmune diseases. Up to date, accumulating data have shown the role of adenosinergic pathway-associated molecules in several types of autoimmune diseases (Table 1).

\section{Rheumatoid arthritis}

Rheumatoid arthritis is a chronic autoimmune disease with joint destruction and severe morbidity. It is characterized by synovial infiltration of inflammatory cells secreting proinflammatory cytokines. By using collagen-induced arthritis (CIA) mouse models, which is a commonly used mouse model for RA study, Chrobak et al. found that response [24]. Taken together, these results demonstrated 
Table 1 Function of adenosine pathway in various autoimmune diseases

\begin{tabular}{|c|c|c|}
\hline AID type & Conclusion & References \\
\hline Rheumatoid arthritis & $\begin{array}{l}\text { Methotrexate unresponsiveness in RA is associated with low expression of CD39 on Treg cells } \\
\text { CD73-deficient mice are significantly more susceptible to collagen-induced arthritis, while this increased } \\
\text { susceptibility of CD73-deficient mice to CIA is reversed by A2AR activation } \\
\text { Serum ADA activity of RA patients is higher compared to that of healthy controls }\end{array}$ & $\begin{array}{l}{[26]} \\
{[25]} \\
{[27]}\end{array}$ \\
\hline $\begin{array}{l}\text { System lupus } \\
\text { erythematosus }\end{array}$ & $\begin{array}{l}\text { CD39 and CD73 expression levels in Treg cells were decreased in active SLE patients as compared to } \\
\text { healthy controls and inactive SLE patients } \\
\text { ADA2 activity and total ADA activity are significantly elevated in serum of SLE patients compared to } \\
\text { healthy control }\end{array}$ & $\begin{array}{l}{[29,30]} \\
{[31]}\end{array}$ \\
\hline $\begin{array}{l}\text { Type I diabetes } \\
\text { mellitus }\end{array}$ & $\begin{array}{l}\text { Diminished A1R expression in pancreatic alpha-cells contributes to the pathology of type } 1 \text { diabetes } \\
\text { A3R activation markedly reduced Beta-TC6 cells proliferation, while this effect was partially blocked by } \\
\text { the A3 antagonist } \\
\text { TLR9 deficiency promotes CD73 expression in T cells and reduces incidence of TIDM in nonobese diabetic } \\
\text { mice }\end{array}$ & $\begin{array}{l}{[53]} \\
{[36]} \\
{[37]}\end{array}$ \\
\hline Multiple sclerosis & $\begin{array}{l}\text { CD73-deficient mice are more resistant to experiment autoimmune encephalomyelitis. A2AR antagonist } \\
\text { protected WT mice from EAE induction through blockage of A2AR signaling }\end{array}$ & {$[38]$} \\
\hline Myasthenia gravis & $\begin{array}{l}\text { Serum ADA activity of MG patients is significantly higher as compared to normal control } \\
\text { Activation of the A2AR attenuates experimental autoimmune myasthenia gravis severity }\end{array}$ & $\begin{array}{l}{[54]} \\
{[45]}\end{array}$ \\
\hline $\begin{array}{l}\text { Autoimmune } \\
\text { hepatitis }\end{array}$ & $\begin{array}{l}\text { In AIH, CD39-positive Tregs are decreased in number and fail to adequately hydrolyze proinflammatory } \\
\text { nucleotides and do not efficiently suppress IL-17 production by effector T cells } \\
\text { The expressions of CD39 and A2AR were significantly diminished in Th17 cells from autoimmune liver } \\
\text { disease patients }\end{array}$ & $\begin{array}{l}{[47]} \\
{[48,55]}\end{array}$ \\
\hline $\begin{array}{l}\text { Juvenile idiopathic } \\
\text { arthritis }\end{array}$ & $\begin{array}{l}\text { Correlation of low CD73 expression on synovial lymphocytes with reduced adenosine generation and } \\
\text { higher disease severity in juvenile idiopathic arthritis }\end{array}$ & [49] \\
\hline Autoimmune uveitis & $\begin{array}{l}\text { A3R agonist can ameliorate the pathological manifestations of the EAU } \\
\text { A2B agonist greatly enhanced the development of EAU }\end{array}$ & $\begin{array}{l}{[51]} \\
{[52]}\end{array}$ \\
\hline
\end{tabular}

CD73-deficient mice were significantly more susceptible to CIA than wild-type (WT) mice. CD73 deficiency resulted in an increased production of pro-inflammatory cytokines (IL-1 $\beta$, IFN- $\gamma$, TNF- $\alpha$, IL-6) in joint and increased joint destruction. In summary, their results demonstrated that CD73 played a protective role in rheumatoid arthritis. In addition, by using A2AR-specific agonist-CGS21680Chrobak also found that stimulation of A2AR in CD73deficient mice resulted in arthritis incidence similar to wild-type mice. These data were supported by other independent studies which showed a beneficial effect of CGS21680 on CIA severity in mice models [25].

Methotrexate (MTX) is the standard first-line therapy of rheumatoid arthritis. However, a significant percentage of rheumatoid arthritis patients are resistant to MTX treatment. Peres et al. [26] found that MTX unresponsiveness in rheumatoid arthritis patients was associated with low expression of CD39 on Treg cells and the deceased suppressive activity of Treg cells through reduced adenosine production. These data suggested that low expression of CD39 on Treg cells could be a biomarker for identifying MTX-resistance rheumatoid arthritis patients. Vinapamula et al. [27] have found that serum ADA levels were higher in rheumatoid arthritis patients $(N=46)$ compared to controls $(N=46)$, which suggested that serum ADA could be as inflammatory marker for rheumatoid arthritis patients. However, we recently investigated the serum ADA levels in 60 rheumatoid arthritis patients and 60 healthy controls (age and sex matched, Chinese people), and our results showed that there was no significant difference of serum ADA in RA patients compared to controls (unpublished data). Up to now, ADA is not a biomarker for RA clinical diagnosis. Thus, further studies in larger number of RA patients are needed to evaluate whether serum ADA can be used as a biomarker for RA patients. Taken together, above results supported that adenosinergic pathway was involved in RA development, diagnosis and therapy.

\section{Systemic lupus erythematosus}

Systemic lupus erythematosus is a systemic autoimmune disease with unknown etiology, which affects almost all the organs and tissues. Increasing evidences have suggested that the disturbed $\mathrm{T}$ cell homeostasis plays a critical role in the development of SLE. Dolff et al. [28] have reported 
that imbalance of Treg and Th cells contributes to the pathogenesis of SLE. Valencia found that the Treg cells number and immunosuppressive activation were significantly decreased in the peripheral blood of patients with active SLE as compared to healthy controls and patients with inactive SLE [11]. Li et al. [29, 30] found that the CD39 and CD73 expressions in Treg cells were decreased in active SLE patients as compared to healthy controls and inactive SLE patients. Notably, the adenosine-generatingenzymes expression levels (CD39, CD73) were found to be decreased, while the activity of adenosine degradation enzyme-ADA-was increased in SLE patients. Saghiri et al. [31] showed that total ADA activity and ADA2 activity (one of ADA isoenzymes) were increased in serum of SLE patients and suggested that ADA and its isoenzymes analysis in serum could be used as a useful and noninvasive marker in evaluation of SLE active phase and disease severity. And moreover, the adenosine receptor has been found to be involved in the progression of SLE. By using MRL/lpr mouse model, which shares many characteristics of human SLE, Zhang et al. found that CGS21680 treatment resulted in significant decrease in albuminuria, hematuria and renal immune complex deposition as well as improvement in renal histology. This result demonstrated that A2AR stimulation ameliorated the severity of nephritis and renal vasculitis in MRL/lpr mouse model and, moreover, suggested that A2AR could be considered as a potential therapeutic target for human lupus nephritis [32]. Taken together, above studies demonstrated that adenosine signaling pathway played an important role during SLE progression.

\section{Type 1 diabetes}

Type 1 diabetes mellitus is an organ-specific autoimmune disease caused by immune-mediated destruction of the insulin-producing pancreatic $\beta$ cells. Accumulating evidences highlight a critical role for the adenosine signaling pathway in the pathophysiology of T1DM [33].

Several studies showed that adenosine could regulate pancreatic $\beta$ cells homeostasis by controlling its proliferation and regeneration. As we know, pancreatic $\beta$ cells are biosensors that detect fluctuations of blood glucose levels and release appropriate amounts of insulin when required. In one of these studies, performed in a zebrafish model, Andersson found that adenosine agonist NECA $\left(5^{\prime}-\mathrm{N}-\right.$ ethylcarboxamidoadenosine) potently increased the regeneration of $\beta$ cells by promoting their proliferation, and NECA's effect on $\beta$ cells proliferation was shown to be mediated by one of zebrafish orthologs of the A2A receptor (called A2aa) [34]. And furthermore, the proliferative and lowering effect of NECA was confirmed in diabetic mice models, suggesting an evolutionarily conserved role for adenosine signaling pathway in $\beta$ cells proliferation. In addition, another study showed that NECA strongly suppressed expression of the proinflammatory cytokines TNF$\alpha$, MIP- $1 \alpha$, IL-12, and IFN- $\gamma$ in pancreata, splenic cells and $\mathrm{T}$ helper 1 lymphocytes, indicating that the benefit of NECA in diabetes therapy was due to immunomodulation [35]. By using mouse pancreatic $\beta$-cell line Beta-TC6, Ohtani found that A3 receptor agonist (Cl-IB-MECA) markedly reduced Beta-TC6 cells proliferation, while this effect of A3 agonist was partially blocked by the A3 antagonist [36]. These results suggested that the A3 receptor was involved in modulation of the survival of pancreatic $\beta$ cells. Moreover, Ohtani also found that adenosine augmented insulin secretion by mouse islets in the presence of either normal or high concentration of glucose via $\mathrm{A} 2 \mathrm{~A}$ receptor, while this stimulatory effect could be blocked by the treatment with $\mathrm{A} 2 \mathrm{~A}$ receptor antagonistSCH58261. Above results suggested that adenosine receptors played an important role in diabetes development and could be potential target for T1DM therapy.

Besides adenosine receptors, CD73, which is a key enzyme for adenosine generation, has also been found to be involved in T1DM development. Tai et al. [37] have showed that TLR9 deficiency in nonobese diabetic mice could significantly protect from T1DM development via up-regulating CD73 expression. This finding indicated that CD73 played an important role in diabetes protection, and might be a therapeutic target for T1DM in humans.

\section{Multiple sclerosis}

Multiple sclerosis is a chronic inflammatory autoimmune disease of the central nervous system (CNS), due to an immune reaction against myelin proteins. The etiology of MS is still unclear. Increasing evidences have suggested that adenosinergic system may be an important factor in MS pathophysiology. Mills et al. demonstrated that CD73deficient mice were more resistant to experiment autoimmune encephalomyelitis (EAE, which is the classical animal model of MS). In addition, it was observed that the infiltration of lymphocytes into CNS in CD73-deficient mice was fewer than that in WT mice. And moreover, they found that SCH58261 protected WT mice from EAE induction through blockage of A2AR signaling. Lymphocyte infiltration into the CNS was diminished in mice treated with A2AR antagonist or through A2AR knockdown [38]. These findings indicate that the activation of CD73 and A2AR is the promotive factors during EAE development via facilitating lymphocyte migration into CNS. Similarly, A2BR expression is increased in MS patients and EAE mice models, and A2BR-specific antagonists (CVT6883 and MRS-1754) can remit of EAE disease and protect the CNS from immune damage [39]. 
However, for the other adenosine receptor-A1R, several lines of evidence have showed that A1R may have the protective function in EAE. Firstly, the expression of A1R is reduced in MS patients [40]. Secondly, A1R-deficient mice show more severe forms of progressive and relapsing EAE compared to WT mice [41]. Thirdly, activation of A1R reduces inflammatory response in the CNS [40]. These results demonstrate the different role of adenosinergic pathway-related molecules in MS development.

\section{Myasthenia gravis}

Myasthenia gravis (MG) is a T cell-dependent autoimmune disease characterized by excessive muscle weakness and fatigue. The experimental autoimmune myasthenia gravis (EAMG) rat is a classic animal model of MG, which can be induced by immunization of rats with the acetylcholine receptor (AChR) R97-116 peptide [42]. As early as in 1990, Chiba et al. [43] reported that the serum ADA activity of MG patients $(n=30)$ was significantly higher as compared to that in normal control $(n=150)$. Oliveira's data showed that serum ADA activity in EMAG animals was significantly higher than that in both control and native animals [44]. We recently investigated the serum ADA activity of MG patients $(n=50)$; however, our results revealed that there was no significant difference between MG patients and healthy controls (unpublished data). Thus, the serum ADA activity should be investigated in more MG patients. Li et al. [45] reported a reduction of A2AR expression in both $\mathrm{T}$ cells and $\mathrm{B}$ cells residing in spleen and lymph nodes following EAMG induction. A2AR stimulation inhibited anti-AChR antibody production and proliferation of AChR-specific lymphocytes in vitro. Furthermore, preventive treatment of EAMG with CGS21680 was effective in down-modulating disease manifestations and therapeutic treatment partly attenuated the severity of established EAMG. In a recent study, Li et al. [46] evaluated adenosine receptor expression in EAMG rats and found that lymphocyte A1R and A2AR expression levels were decreased, while there was no significant change in A2BR and A3R expressions. Thus, $\mathrm{Li}$ et al's [44] data demonstrated the critical role of A2AR during $\mathrm{MG}$ progression and presented the potential opportunities to develop A2AR targeting therapeutic approach. Recently, Oliveira found that $\mathrm{CD} 4{ }^{+} \mathrm{CD} 25^{+-}$ $\mathrm{FoxP}^{+}$regulatory $\mathrm{T}$ cells of EAMG expressed lower amount of CD73 as compared to controls. The reduction of CD73 expression and adenosine receptors in EMAG rats strongly suggests that the adenosine signaling pathway may be the dysfunction during MG progression. Thus, stimulation of CD73 or A2AR may have therapeutic potential in MG.

\section{Autoimmune hepatitis}

Autoimmune hepatitis is an inflammatory disease of the liver, characterized by female preponderance, interface hepatitis on histology and autoantibody positivity. Numerical and functional defects of Treg cells are likely to play a permissive pathogenic role in AIH. Several lines of evidence have demonstrated the role of adenosine pathway in AIH. Grant et al. [47] found that the number of CD39+ Treg cells was decreased in $\mathrm{AIH}$, which resulted in failure to efficiently suppress IL-17 production by effector T cells. In a recent study, Liberal et al. [48] reported that the expression of CD39 and A2AR was significantly diminished in Th17 cells from autoimmune liver disease patients, and these decreases were associated with impaired generation of immunosuppressive adenosine and defective regulatory properties. These data indicated that adenosinergic pathway involved in AIH development by impairing the immune regulatory function of Treg and Th cells.

\section{Other autoimmune diseases}

Juvenile idiopathic arthritis is a chronic autoimmune rheumatic disease of childhood with unknown etiology, characterized by swelling of the joints and thickening of synovial lining. Botta et al. [49] found that the expression level of CD73 on synovial fluid mononuclear cells (SFMCs) from JIA patients was lower than that in peripheral blood mononuclear cells (PBMCs) from both JIA patients and healthy controls. And moreover, low expression of CD73 on $\mathrm{T}$ and $\mathrm{B}$ cells in inflamed site is correlated with the clinical severity of JIA patients. This finding suggested that the decreased CD73 expression in SFMCs would lead to a decreased potential for anti-inflammatory activity and then, the deterioration of disease.

Uveitis is an inflammation involving the middle layer of the eye with a high risk of blindness, which can be caused by autoimmune disorder and infection. Experiment autoimmune uveitis (EAU) is a mouse model of endogenous uveitis in humans. In recent years, several studies reported the role of adenosinergic pathway in uveitis by using EAU models. Liang et al. [50] found that $\gamma \delta \mathrm{T}$ cells expressed different amounts of CD73 during the different stages of EAU. However, the function of CD73 expression in uveitis has not been well demonstrated. Bar-Yehuda et al. found that treatment with the highly selective A3R agonist-CF101—can ameliorate the pathological manifestations of the EAU. This result supported further exploration of CF101 for the uveitis therapy [51]. However, unlike the A3R agonist, Chen et al. [52] showed that selective A2B agonist greatly enhanced the development of EAU, whereas treatment with A2B antagonist significantly ameliorated severity of EAU. Taken together, these data 
suggested the different effect of the adenosine receptor subtypes involved in uveitis development.

\section{Conclusion}

Autoimmune diseases are caused by disruption of natural immune homeostasis and failure of immune tolerance. Under natural circumstance, the immunosuppressive signal and stimulative signal inter-restrict with each other and maintain the immune homeostasis together. While, the immunosuppressive effects of adenosine present the potential roles of adenosinergic pathway in the development of autoimmune diseases. Indeed, in recent years, increasing data support that adenosinergic pathway plays an important role in various types of autoimmune diseases, and moreover, this discovery shed new light on the diagnosis, monitoring and therapy of certain autoimmune diseases. For diagnosis and monitoring, the increased serum ADA activity in RA and SLE patients present the potential value of serum ADA level that served as a biomarker. For therapy, the connection between low CD39 expression in RA patients and methotrexate unresponsiveness suggests that CD39 expression analysis can be used to identify methotrexate-responsive RA patients. And moreover, some agonist/antagonist of adenosine receptors has displayed favorable curative effect in animal models. Notably, The CF101, which is the specific agonist of A3R, is currently undergoing testing in clinical trials for the treatment of rheumatoid arthritis patients [56, 57]. Although other agonist of adenosine receptors has not been translated into clinical patients, the results in animal models have revealed that adenosine receptors target therapy may be an alternative and realistic therapeutic approach for autoimmune diseases in the future. Thus, future studies aiming at translating adenosinergic pathway target therapy into clinical patients can be expected. Notably, the cardiovascular side effects of a A2AR agonist-GW328267X — have been found in clinical trials of chronic obstructive pulmonary disease treatment [3]. Thus, because of multiple effects of adenosinergic signaling on immune system, although adverse events has not yet been observed in animal models of autoimmune diseases, the potential toxic risk of adenosinergic pathway target therapy cannot be ignored and must be argued carefully before translating into autoimmune disease patients. Up to now the total studies focused on the role of adenosinergic pathway in human autoimmune diseases are still few, and more studies are required to completely evaluate the adenosinergic pathway and its contribution in autoimmune disease development.
Acknowledgments This work is supported by the National Natural Science Fund of China (No. 81572974).

\section{Compliance with ethical standard}

Conflict of Interests The authors declare that there is no conflict of interests regarding the publication of this paper.

Open Access This article is distributed under the terms of the Creative Commons Attribution 4.0 International License (http:// creativecommons.org/licenses/by/4.0/), which permits unrestricted use, distribution, and reproduction in any medium, provided you give appropriate credit to the original author(s) and the source, provide a link to the Creative Commons license, and indicate if changes were made.

\section{References}

1. Margo CE, Harman LE. Autoimmune disease: conceptual history and contributions of ocular immunology. Surv Ophthalmol. 2016;. doi:10.1016/j.survophthal.2016.04.006.

2. Liebman HA. Immune modulation for autoimmune disorders: evolution of therapeutics. Semin Hematol. 2016;53(Suppl 1): S23-6. doi:10.1053/j.seminhematol.2016.04.008.

3. Hasko G, Linden J, Cronstein B, Pacher P. Adenosine receptors: therapeutic aspects for inflammatory and immune diseases. Nat Rev Drug Discovery. 2008;7(9):759-70. doi:10.1038/nrd2638.

4. Hasko G, Cronstein BN. Adenosine: an endogenous regulator of innate immunity. Trends Immunol. 2004;25(1):33-9.

5. Wang D, Huang S, Yuan X, Liang J, Xu R, Yao G, et al. The regulation of the Treg/Th17 balance by mesenchymal stem cells in human systemic lupus erythematosus. Cell Mol Immunol. 2015;. doi:10.1038/cmi.2015.89.

6. Ohl K, Tenbrock K. Regulatory T cells in systemic lupus erythematosus. Eur J Immunol. 2015;45(2):344-55. doi:10.1002/eji. 201344280.

7. Alunno A, Bartoloni E, Bistoni O, Nocentini G, Ronchetti S, Caterbi S, et al. Balance between regulatory $\mathrm{T}$ and Th17 cells in systemic lupus erythematosus: the old and the new. Clin Dev Immunol. 2012;2012:823085. doi:10.1155/2012/823085.

8. Yang J, Yang X, Zou H, Chu Y, Li M. Recovery of the immune balance between Th17 and regulatory $\mathrm{T}$ cells as a treatment for systemic lupus erythematosus. Rheumatology (Oxford, England). 2011;50(8):1366-72. doi:10.1093/rheumatology/ker116.

9. Yang J, Chu Y, Yang X, Gao D, Zhu L, Yang X, et al. Th17 and natural Treg cell population dynamics in systemic lupus erythematosus. Arthritis Rheum. 2009;60(5):1472-83. doi:10.1002/art. 24499.

10. Martin JC, Baeten DL, Josien R. Emerging role of IL-17 and Th17 cells in systemic lupus erythematosus. Clin Immunol (Orlando, Fla). 2014;154(1):1-12. doi:10.1016/j.clim.2014.05.004.

11. Valencia $X$, Yarboro $C$, Illei G, Lipsky PE. Deficient $\mathrm{CD} 4+\mathrm{CD} 25$ high $\mathrm{T}$ regulatory cell function in patients with active systemic lupus erythematosus. J Immunol (Baltimore, Md: 1950). 2007;178(4):2579-88.

12. Vincent FB, Northcott M, Hoi A, Mackay F, Morand EF. Clinical associations of serum interleukin-17 in systemic lupus erythematosus. Arthritis Res Ther. 2013;15(4):R97. doi:10.1186/ $\operatorname{ar} 4277$.

13. Roeleveld DM, Koenders MI. The role of the Th17 cytokines IL-17 and IL-22 in Rheumatoid Arthritis pathogenesis and developments in cytokine immunotherapy. Cytokine. 2015;74(1): 101-7. doi:10.1016/j.cyto.2014.10.006. 
14. Gaffen SL. The role of interleukin-17 in the pathogenesis of rheumatoid arthritis. Curr Rheumatol Rep. 2009;11(5):365-70.

15. Chen R, Tao Y, Qiu K, Huang W, Huang C, Li J. [Association of circulating Treg cells with disease activity in patients with rheumatoid arthritis]. Nan fang yi ke da xue xue bao $=$ J South Med Univ. 2012;32(6):886-9.

16. Cabrera SM, Rigby MR, Mirmira RG. Targeting regulatory $T$ cells in the treatment of type 1 diabetes mellitus. Curr Mol Med. 2012;12(10):1261-72.

17. Antonioli L, Pacher P, Vizi ES, Hasko G. CD39 and CD73 in immunity and inflammation. Trends Mol Med. 2013;19(6): 355-67. doi:10.1016/j.molmed.2013.03.005.

18. Nguyen MD, Ross AE, Ryals M, Lee ST, Venton BJ. Clearance of rapid adenosine release is regulated by nucleoside transporters and metabolism. Pharmacol Res Perspect. 2015;3(6):e00189. doi:10.1002/prp2.189.

19. Antonioli L, Fornai M, Colucci R, Ghisu N, Tuccori M, Del Tacca $\mathrm{M}$, et al. Regulation of enteric functions by adenosine: pathophysiological and pharmacological implications. Pharmacol Ther. 2008;120(3):233-53. doi:10.1016/j.pharmthera.2008.08.010.

20. Romio M, Reinbeck B, Bongardt S, Huls S, Burghoff S, Schrader J. Extracellular purine metabolism and signaling of CD73derived adenosine in murine Treg and Teff cells. Am J Physiol Cell Physiol. 2011;301(2):C530-9. doi:10.1152/ajpcell.00385. 2010.

21. Smyth LA, Ratnasothy K, Tsang JY, Boardman D, Warley A, Lechler R, et al. CD73 expression on extracellular vesicles derived from $\mathrm{CD} 4+\mathrm{CD} 25+$ Foxp3 $+\mathrm{T}$ cells contributes to their regulatory function. Eur J Immunol. 2013;43(9):2430-40. doi:10.1002/eji.201242909.

22. Ohta A, Kini R, Ohta A, Subramanian M, Madasu M, Sitkovsky M. The development and immunosuppressive functions of CD4 $(+)$ $\mathrm{CD} 25(+)$ FoxP3(+) regulatory $\mathrm{T}$ cells are under influence of the adenosine-A2A adenosine receptor pathway. Front Immunol. 2012;3:190. doi:10.3389/fimmu.2012.00190.

23. Hasko G, Pacher P. Regulation of macrophage function by adenosine. Arterioscler Thromb Vasc Biol. 2012;32(4):865-9. doi:10.1161/atvbaha.111.226852.

24. Liu C, Shang Q, Bai Y, Guo C, Zhu F, Zhang L, et al. Adenosine A2A receptor, a potential valuable target for controlling reoxygenated DCs-triggered inflammation. Mol Immunol. 2015;63(2): 559-65. doi:10.1016/j.molimm.2014.10.012.

25. Chrobak P, Charlebois R, Rejtar P, El Bikai R, Allard B, Stagg J. CD73 plays a protective role in collagen-induced arthritis. J Immunol (Baltimore, Md: 1950). 2015;194(6):2487-92. doi:10. 4049/jimmunol.1401416.

26. Peres RS, Liew FY, Talbot J, Carregaro V, Oliveira RD, Almeida $\mathrm{SL}$, et al. Low expression of CD39 on regulatory $\mathrm{T}$ cells as a biomarker for resistance to methotrexate therapy in rheumatoid arthritis. Proc Natl Acad Sci USA. 2015;112(8):2509-14. doi:10. 1073/pnas.1424792112.

27. Vinapamula KS, Pemmaraju SV, Bhattaram SK, Bitla AR, Manohar SM. Serum adenosine deaminase as inflammatory marker in rheumatoid arthritis. J Clin Diagn Res JCDR. 2015;9(9): Bc08-10. doi:10.7860/jcdr/2015/14296.6483.

28. Dolff S, Bijl M, Huitema MG, Limburg PC, Kallenberg CG, Abdulahad WH. Disturbed Th1, Th2, Th17 and T(reg) balance in patients with systemic lupus erythematosus. Clin Immunol (Orlando, Fla). 2011;141(2):197-204. doi:10.1016/j.clim.2011.08. 005 .

29. Li DM, Li XP, Li XM, Wang GS, Ma Y, Zhao SS, et al. Expression of FOXP3 in CD4 + CD39 + T cells of patients with systemic lupus erythematosus and dynamic observation of treatment with glucocorticoid. Zhonghua yi xue za zhi. 2009;89(23): 1636-8.
30. Li DM, Li XP, Zhang JH, Hu SR, Xiao B, Chen W, et al. The expression of CD73 in CD4 + regulatory T cells in patients with new-onset systemic lupus erythematosus. Zhonghua nei ke za zhi. 2010;49(9):772-5.

31. Saghiri R, Ghashghai N, Movaseghi S, Poursharifi P, Jalilfar S, Bidhendi MA, et al. Serum adenosine deaminase activity in patients with systemic lupus erythematosus: a study based on ADA1 and ADA2 isoenzymes pattern. Rheumatol Int. 2012;32(6): 1633-8. doi:10.1007/s00296-011-1836-8.

32. Zhang L, Yang N, Wang S, Huang B, Li F, Tan H, et al. Adenosine $2 \mathrm{~A}$ receptor is protective against renal injury in MRL/lpr mice. Lupus. 2011;20(7):667-77. doi:10.1177/0961203310 393262.

33. Antonioli L, Blandizzi C, Csoka B, Pacher P, Hasko G. Adenosine signalling in diabetes mellitus-pathophysiology and therapeutic considerations. Nat Rev Endocrinol. 2015;11(4):228-41. doi:10.1038/nrendo.2015.10.

34. Andersson O. Role of adenosine signalling and metabolism in beta-cell regeneration. Exp Cell Res. 2014;321(1):3-10. doi:10. 1016/j.yexcr.2013.11.019.

35. Nemeth ZH, Bleich D, Csoka B, Pacher P, Mabley JG, Himer L, et al. Adenosine receptor activation ameliorates type 1 diabetes. FASEB J. 2007;21(10):2379-88. doi:10.1096/fj.07-8213com.

36. Ohtani M, Oka T, Ohura K. Possible involvement of A(2)A and $\mathrm{A}(3)$ receptors in modulation of insulin secretion and beta-cell survival in mouse pancreatic islets. Gen Comp Endocrinol. 2013;187:86-94. doi:10.1016/j.ygcen.2013.02.011.

37. Tai N, Wong FS, Wen L. TLR9 deficiency promotes CD73 expression in $\mathrm{T}$ cells and diabetes protection in nonobese diabetic mice. J Immunol (Baltimore, Md: 1950). 2013;191(6):2926-37. doi:10.4049/jimmunol.1300547.

38. Mills JH, Thompson LF, Mueller C, Waickman AT, Jalkanen S, Niemela $J$, et al. CD73 is required for efficient entry of lymphocytes into the central nervous system during experimental autoimmune encephalomyelitis. Proc Natl Acad Sci USA. 2008;105(27):9325-30. doi:10.1073/pnas.0711175105.

39. Wei W, Du C, Lv J, Zhao G, Li Z, Wu Z, et al. Blocking A2B adenosine receptor alleviates pathogenesis of experimental autoimmune encephalomyelitis via inhibition of IL-6 production and Th17 differentiation. J Immunol (Baltimore, Md: 1950). 2013;190(1):138-46. doi:10.4049/jimmunol.1103721.

40. Johnston JB, Silva C, Gonzalez G, Holden J, Warren KG, Metz $\mathrm{LM}$, et al. Diminished adenosine A1 receptor expression on macrophages in brain and blood of patients with multiple sclerosis. Ann neurol. 2001;49(5):650-8.

41. Tsutsui S, Schnermann J, Noorbakhsh F, Henry S, Yong VW, Winston BW, et al. A1 adenosine receptor upregulation and activation attenuates neuroinflammation and demyelination in a model of multiple sclerosis. J Neuro sci off J Soc Neurosci. 2004;24(6):1521-9. doi:10.1523/jneurosci.4271-03.2004.

42. Link H, Xiao BG. Rat models as tool to develop new immunotherapies. Immunol Rev. 2001;184:117-28.

43. Chiba S, Matsumoto H, Motoi Y, Miyano N, Kashiwagi M. High serum adenosine deaminase activity and its correlation with lymphocyte subsets in myasthenia gravis. J Neurol Sci. 1990;100(1-2): 174-7.

44. Oliveira L, Correia A. Deficits in endogenous adenosine formation by ecto- $5^{\prime}$-nucleotidase/CD73 impair neuromuscular transmission and immune competence in experimental autoimmune myasthenia gravis. Mediators Inflamm. 2015;2015:460610. doi:10.1155/2015/460610.

45. Li N, Mu L, Wang J, Zhang J, Xie X, Kong Q, et al. Activation of the adenosine $\mathrm{A} 2 \mathrm{~A}$ receptor attenuates experimental autoimmune myasthenia gravis severity. Eur J Immunol. 2012;42(5):1140-51. doi:10.1002/eji.201142088. 
46. Li N, Wang G, Yao X, Kong Q, Shang X, Xie X, et al. Adenosine receptor expression in a rat model of experimental autoimmune myasthenia gravis. Cell Immunol. 2014;290(2):217-25. doi:10. 1016/j.cellimm.2014.07.005.

47. Grant CR, Liberal R, Holder BS, Cardone J, Ma Y, Robson SC, et al. Dysfunctional CD39(POS) regulatory $\mathrm{T}$ cells and aberrant control of T-helper type 17 cells in autoimmune hepatitis. Hepatology (Baltimore, MD). 2014;59(3):1007-15. doi:10.1002/ hep.26583.

48. Liberal R, Grant CR, Ma Y, Csizmadia E, Jiang ZG, Heneghan MA, et al. CD39 mediated regulation of Th17-cell effector function is impaired in juvenile autoimmune liver disease. J Autoimmun. 2016;. doi:10.1016/j.jaut.2016.05.005.

49. Botta Gordon-Smith S, Ursu S, Eaton S, Moncrieffe H, Wedderburn LR. Correlation of low CD73 expression on synovial lymphocytes with reduced adenosine generation and higher disease severity in juvenile idiopathic arthritis. Arthritis Rheumatol (Hoboken, NJ). 2015;67(2):545-54. doi:10.1002/art. 38959.

50. Liang D, Zuo A, Zhao R, Shao H, Born WK, O’Brien RL, et al. CD73 expressed on gammadelta $\mathrm{T}$ cells shapes their regulatory effect in experimental autoimmune uveitis. PLoS ONE. 2016;11(2): e0150078. doi:10.1371/journal.pone.0150078.

51. Bar-Yehuda S, Luger D, Ochaion A, Cohen S, Patokaa R, Zozulya $\mathrm{G}$, et al. Inhibition of experimental auto-immune uveitis by the A3 adenosine receptor agonist CF101. Int $\mathrm{J}$ Mol Med. 2011; 28(5):727-31. doi:10.3892/ijmm.2011.753.
52. Chen M, Liang D, Zuo A, Shao H, Kaplan HJ, Sun D. An A2B adenosine receptor agonist promotes Th17 autoimmune responses in experimental autoimmune uveitis (EAU) via dendritic cell activation. PLoS ONE. 2015;10(7):e0132348. doi:10.1371/ journal.pone.0132348.

53. Yip L, Taylor C, Whiting CC, Fathman CG. Diminished adenosine A1 receptor expression in pancreatic alpha-cells may contribute to the pathology of type 1 diabetes. Diabetes. 2013;62(12): 4208-19. doi:10.2337/db13-0614.

54. Chiba S, Saitoh M, Kashiwagi M, Kobayashi N, Matsumoto H. Isozyme analysis of the high serum adenosine deaminase activity in patients with myasthenia gravis. Intern Med (Tokyo, Japan). 1995;34(2):81-4.

55. Chouker A, Thiel M, Lukashev D, Ward JM, Kaufmann I, Apasov $\mathrm{S}$, et al. Critical role of hypoxia and $\mathrm{A} 2 \mathrm{~A}$ adenosine receptors in liver tissue-protecting physiological anti-inflammatory pathway. Mol Med (Cambridge, Mass). 2008;14(3-4):116-23. doi:10.2119/ 2007-00075.Chouker.

56. Fishman P, Cohen S. The A3 adenosine receptor (A3AR): therapeutic target and predictive biological marker in rheumatoid arthritis. Clin Rheumatol. 2016;35(9):2359-62. doi:10.1007/ s10067-016-3202-4.

57. Silverman MH, Strand V, Markovits D, Nahir M, Reitblat T, Molad Y, et al. Clinical evidence for utilization of the A3 adenosine receptor as a target to treat rheumatoid arthritis: data from a phase II clinical trial. J Rheumatol. 2008;35(1):41-8. 